\title{
Insucesso escolar e auto-avaliação na adolescência*
}

\author{
MANUELA FLEMING / EURICO FIGUEIREDO / ÂNGELA MAIA / \\ ALDA SOUSA**
}

\section{INTRODUÇÃO}

Podemos falar de insucesso escolar sempre que o rendimento escolar é inferior ao desejado ou esperado. Nesse sentido ele não existe apenas quando o aluno não transita de ano, mas igualmente nas situações em que as notas obtidas não correspondem às expectativas. No nosso trabalho abordaremos o fenómeno do Insucesso Escolar através do prisma das reprovaçôes escolares e da auto-avaliaçäo, indicadores que naturalmente não o exprimem em toda a sua complexidade.

Historicamente e nas sociedades ocidentais contemporâneas o Insucesso Escolar começou por ser avaliado como um fenómeno centrado na criança. As variáveis estudadas são ligadas a factores internos como seja a debilidade, a preguiça, problemas de psicomotricidade, perturbaçőes neuróticas da personalidade. Paralelamente, e com maior reflexo no final dos anos 60 , alguns estudos debruçaram-

\footnotetext{
* Este trabalho insere-se numa Investigação mais ampla, subsidiada pela C.I. da Reitoria da Universidade do Porto (Investigação $\mathrm{n}^{2} 110 / 85 / 86$ ).

** M.F., Psicóloga, ICBAS (Universidade do Porto); E.F., Professor Catedrático de Psiquiatria, ICBAS. Responsáveis pelo Projecto de Investigação.

A. M., Assistente Estagiária, FPCE (Universidade do Porto) e A.S., Assistente Convidada, ICBAS, colaboraram respectivamente na revisão bibliográfica e no tratamento estatístico dos dados. Agradece-se a colaboração prestada pelo Doutor José Miguez, da FPCE (Universidade do Porto), ao Projecto de Investigação.
}

-se sobre questões familiares e relacionaram o insucesso com um conjunto de variáveis da família, nomeadamente o nível cultural dos pais, ambições familiares, práticas educativas, etc. O handicap linguístico ou handicap sócio-cultural mais vasto foi também apontado como causa de insucesso, por tornar a criança incompetente na situação escolar. A partir das concepções teóricas elaboradas surgiram diversas intervenções: centradas na criança e baseadas em concepções de causalidade interna ou familiar; de orientação sistémica, reformulando o problema do insucesso num contexto de perturbação do sistema familiar; baseadas em programas de compensação dos handicaps culturais, dirigidos às crianças de nível sócio-cultural considerado «baixo».

Os trabalhos sobre a família estenderam-se pelos anos 70 , bem como os trabalhos centrados sobre a criança. Foram ainda surgindo, a par das explicações psicológicas e psicanalíticas, as concepções psicossociológicas. Talvez tenha sido o grande número de alunos em situação de insucesso que alertou os investigadores para o facto de dificilmente as causas individuais ou familiares poderem explicar percentagens tão elevadas como $40 \%$ ou $50 \%$ de instucesso. Pereira e Martins (1978) reflectem esta aproximação do fenómeno insucesso ao apontarem a escola como uma situação em que há reprodução do sistema social. «...Estamos convencidos que o insucesso escolar não define um problema simplesmente técnico, mas sim um problema que se articula à instância do Político - 
querendo nós por «político» significar aquilo que não só se relaciona directamente com o aparclho de Estado, mas que também tem a ver com conflitos culturais, relações de poder de âmbito microssocial, zonas de friç̧ão entre espaços subculturais diferenciados, etc.» (pág. 5). A escola é então conceptualizada como reprodução do sistema social, hierarquizado, e em que a selecção é um fenómeno intrínseco.

Actualmente são várias as perspectivas tcóricas que orientam a investigação e encontram-se numerosos trabalhos sobre: 1 . estudo da relação entre aspectos da personalidade e o insucesso escolar; 2. as dimensões sociológica e pedagógica do insucesso, na perspectiva institucional; 3 . o problema das atribuições do sucesso-insucesso; 4. a avaliação da influĉncia dos factores familiares no insucesso.

O nosso trabalho, pela própria natureza das variáveis que estuda (familiares e demográficas), constitui-se como um contributo para esta tcreeira linha de investigação.

Varios estudos, cuja referência exaustiva não cabe fazer aqui, têm tentado esclarecer a importûncia de características familiares para o fenómeno do insucesso escolar. Ao fazcrmos refcrência a alguns desses trabalhos não pretendemos encontrar e conceptualizar as características familiares causádoras do insucesso mas sim as variáveis, condições ou circunstâncias (no sentido de Leităo e Abreu, 1985) do fenómeno.

\section{ATITUDES FAMILIARES E INSUCESSO ESCOLAR}

Morrow et. al. (1961) numa rcvisão de literatura referc que têm sido associadas ao sucesso escolar situaçōes familiares de suporte emocional como sejam: aprovação, maior interesse e compreensão, próximidade dos pais em relação aos filhos, maior sentido de pertença à família, maior identificação com os pais. A não realização escolar estaria associada a pais dominadores ou super-restritivos, a punição severa e ineficaz ou a excesso de zelo. A tensão no lar e o desacordo entre os pais em relação aos comportamentos esperados dos filhos estariam associados ao insucesso. O mesmo autor conclui que a partitha de decisão quanto à ocupação de tcmpos livres e a partilha de confidências e idcias estão associadas ao sucesso, bem como a harmonia entre os pais, o afccto pais/filhos, a aceitação, a confiança e aprovação; enquanto o insucesso parcce ligado ao maior domínio, scveridade e restrição por parte dos pais. Cervantes (1965, citado por Stucki, 1983) refere que as famílias com insucesso escolar nos filhos seriam pouco solidárias e pouco sociávcis, rejcitando os seus filhos e os seus amigos. Autores de oricntação comportamental tomaram em consideração as atitudes familiares como a autoridade parental ou interesse pelo trabalho escolar das crianças, concluindo igualmente que atitudes extremas de protecção e ajuda ou de intolerância seriam prejudiciais.

Finalmente foi salientado por alguns autores que o insucesso está frequentemente associado a situações em que o adolescente se sente incapaz de corresponder às expectativas dos pais ou estes serem percebidos como hostis ou desinteressados (Berzonsky, 1981).

\section{CARACTERÍSTICAS DEMOGRÁFICAS DA FAMILLIA E INSUCESSO ESCOLAR}

A associação do insucesso escolar ao nível sócio-cultural baixo dos pais é referido por vários trabalhos (Grácio e Miranda, 1977; Rafolovich, 1980; Avanzini; Leitão e Abreu, 1985). Na perspectiva de Avanzini, o nível cultural dos pais condiciona a adaptação escolar, pois a sensibilização aos interesses escolares, a informação de que a criança dispõe, o vocabulário, os livros, o acompanhamento do trabalho cscolar, ć facilitado pelo nível cultural. Leitão e Abreu (1985) acrescentam (a partir dos dados por eles encontrados) que a variável habilitação escolar «deve ser interpretada não apenas em termos das condições ou circunstâncias externas, mas também $\mathrm{cm}$ termos de processos psicológicos directamente ligados aos comportamentos interpessoais, à comunicação de atitudes, de expectativas e de aspirações, processos psicológicos de comunicação interpessoal que teriam nas mães agentes mais eficazes que nos pais» (pág. 142).

O facto de a mãe trabalhar ou estar em casa tem sido também estudado (Rafolovich, 1980), verificando este autor que os filhos das mães que trabalham têm melhor rendimento escolar, mas este é especialmente uma função da categoria sócio- 
-profissional dos pais. Igualmente verificou que quanto maior for o nível de estudos da mãe, melhor será o rendimento do filho independentemente da mãe trabalhar ou não.

\section{METODOLOGIA}

\section{AMOSTRA}

Partimos de uma amostra estabelecida a partir do universo total de estudantes do ensino oficial, ciclo preparatório e secundário, com mais de 12 anos de idade e frequentando os oito estabelecimentos de ensino do concelho de Matosinhos, no ano de 1984/ $/ 85$.

A amostra, construída segundo critérios de representatividade, é constituída por 994 sujeitos, $51 \%$ de rapazes e $49 \%$ de raparigas e apresentando a seguinte distribuição por idades e por Escolas:

Distribuiçáo por idades

\begin{tabular}{|c|c|c|}
\hline IDADE & $\mathrm{n}$ & $\mathrm{p}$ \\
\hline 12 anos & 307 & 31 \\
\hline 13 & 242 & 24 \\
\hline 14 & 135 & 14 \\
\hline 15 & 109 & 11 \\
\hline 16 & 77 & 8 \\
\hline 17 & 64 & 6 \\
\hline 18 & 41 & 4 \\
\hline 19 & 19 & 2 \\
\hline Total & 994 & 100 \\
\hline
\end{tabular}

Distribuição por escolas

\begin{tabular}{|c|c|c|c|}
\hline & ESCOLAS & $\mathrm{n}$ & $\mathrm{P}$ \\
\hline \multirow{2}{*}{$\begin{array}{c}\text { Prep. } \\
\quad »\end{array}$} & S. Mamede & 65 & 7 \\
\hline & Leça & 118 & 12 \\
\hline \multirow{2}{*}{$\begin{array}{l}\gg \\
»\end{array}$} & Matosinhos (A. Nobre) & 85 & 9 \\
\hline & Senhora da Hora & 162 & 16 \\
\hline \multirow{2}{*}{$\begin{array}{c}\text { Sec. } \\
\#\end{array}$} & $\mathrm{n}^{0} 2$ & 239 & 24 \\
\hline & Leça & 59 & 6 \\
\hline \multirow{3}{*}{ 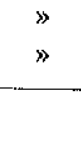 } & Padräo & 174 & 18 \\
\hline & $\mathrm{n}^{\mathrm{o}} 1$ & 92 & 9 \\
\hline & Total & 994 & 100 \\
\hline
\end{tabular}

\section{INSTRUMENTO}

Usámos como instrumento, o questionário anónimo, individual, auto-preenchido e passado $\mathrm{cm}$ situação escolar. O questionário continha ítems de caracterização do sujeito ao nível do scu aproveitamento escolar e da sua família.

\section{OBJECTIVOS, ANÁLISE DOS DADOS E RESULTADOS OBTIDOS}

\section{OBJECTIVOS}

$\mathrm{Na}$ análise do fenómeno Insucesso Escolar na população de adolescentes por nós estudada tomamos como variáveis indicadoras de insucesso o número de reprovaçóes escolares obtidas pelo aluno desde a sua entrada no ensino básico e a avaliação que o adolescente faz do seu proprio sucessolinsucesso escolar. Esta última questão foi formulada do seguinte modo: «Duma forma geral como avalia o seu aproveitamento escolar?», podendo o aluno responder numa escala de Muito Bom a Mau.

A análise das associações de cada uma destas variáveis com outras características de sujeito, e entre si, permitirá uma compreensão do fenómeno segundo uma dupla perspectiva: a do insucesso administrativo (as reprovações) e a do insucesso sentido pelo adolescente (como se avalia).

Pretende-se pôr em evidência a contribuição, para o fenómeno do sucesso/insucesso escolar, de factores de ordem familiar, nomeadamente os que se relacionam com a composição do anel familiar do adolescente (dada pclas variáveis: presença/ ausência dos pais e inserção familiar) e com o nível sócio-económico e cultural dos pais (dada pclas variáveis: estatuto profissional e grau de instrução).

Assim, na análise estatística dos resultados, tomaremos como variáveis independentes as seguintes:

- Sexo

- Composição do anel familiar (presença/ausência de um ou de ambos os pais, por falecimento) rados)

- Siluação conjugal dos pais (casados ou sepa-

- Inserção familiar (com qucm vive o sujeito)

- Posição na fratria 
- Situação dos pais face ao trabalho (com emprego/sem emprego)

- Estatuto profissional dos pais (")

- Grau de instrução dos pais.

\section{ANÁLISE DAS REPROVAÇÕES ESCO- LARES}

\subsection{Características do fenómeno}

$\mathrm{Na}$ análise do fenómeno das reprovações verificou-se que na população estudada, $57,5 \%$ dos adolescentes tinham pelo menos 1 reprovação e que $25 \%$ dos adolescentes tinham 2 ou mais reprovaçōes (Quadro 1)

Quadro 1

Distribuição dos Sujeitos em função do Número de Reprovaçöes

\begin{tabular}{|lrr|}
\hline \multicolumn{1}{|c}{ REPROVAÇÕES } & $\mathrm{n}$ & $\mathrm{P}(\%)$ \\
\hline Nenhuma Reprovação & \multicolumn{1}{c|}{419} & 42.5 \\
1 Reprovação & 322 & 32.7 \\
2 Reprovações & 178 & 18.1 \\
3 ou mais Reprovações & 67 & 6.8 \\
\hline
\end{tabular}

\subsection{Contribuição das variáveis em estudo pa- ra o fenómeno}

Procurámos as associações estatisticamente significativas entre o número de reprovaçōes escolares e as variáveis em estudo. Essa análise permitiu apurar o seguinte:

- O insucesso escolar não está associado de forma estatisticamente significativa com as seguintes variáveis: auto-avaliação do aproveitamento escolar; composição do anel familiar; situação conjugal dos pais; inserção familiar; situação dos pais face ao trabalho.

- $O$ insucesso escolar, analisado pelo número de reprovações, está associado duma forma estatisticamente significativa, com as seguintes variáveis: sexo; posiçăo na fratria; estatuto profissional dos pais; grau de instruções. Os graus de significância são apresentados no Quadro 2.

\section{Sexo}

Verifica-se uma associação entre o facto de ter sofrido reprovações e o sexo masculino. Assim, quando comparado o grupo de sujeitos sem nenhuma reprovação e o grupo de sujeitos com pelo menos 1 reprovação constata-se que, neste último, a

Quadro 2

Associação Estatisticamente significativa entre as Reprovaçöes Escolares e Variáveis relativas ao Sujeito (Teste $X^{2}$ )

\begin{tabular}{|lrrr|}
\hline & \multicolumn{1}{c}{ X2 } & G.L. & P \\
\hline Sexo & 4.827 & 1 & $0.028 *$ \\
Posição na Fratria & 8.491 & 3 & $0.037 *$ \\
Estatuto Profissional do Pai & 40.420 & 12 & $0.000 * * *$ \\
Estatuto Profissional da Mãe & 39.254 & 15 & $0.001 * * * *$ \\
Grau de Instrução do Pai & 55.610 & 9 & $0.000 * * *$ \\
Grau de Instrução da Mãe & 58.788 & 9 & $0.000 * * *$ \\
\hline
\end{tabular}

* $\mathrm{P}<0.05 ; * * \mathrm{P}<0.01 ; * * * \mathrm{P}<0.001$

(1) Na avaliação do estudo profissional dos pais seguiu-se uma classificação numa escala de 1 a 5 , em que, dando exemplos, na categoria 1 se inclui: Quadros Superiores da Administraçāo, Liccnciados com alta posiçāo; na categoria 2: Licenciados com posiçāo média, Proprietários de pequenas indústrias; na categoria 3: Comerciantes e vendedores da pequena indústria, empregados de escritorio, comércio e indústria; na categoria 4: operários e trabalhadores qualificados, Comerciantes de ínfima categoria; e na categoria 5: Trabalhadores não especializados, Contínuos. Na classificação das mães, juntou-se urna outra categoria de «Mães domésticas». 
proporção de rapazes é significativamente superior à das raparigas $(\mathrm{P}<.05)$.

Quadro 3

Distribuição dos Sujeitos em função do Sexo $e$ do Número de Reprovaçóes

\begin{tabular}{|lrcrr|}
\hline \multirow{2}{*}{ REPROVAÇÕES } & \multicolumn{2}{c}{ S. Masculino } & \multicolumn{2}{c|}{ S. Feminino } \\
& $\mathrm{n}$ & $(\%)$ & \multicolumn{1}{c|}{$\mathrm{n}$} & $(\%)$ \\
\hline Nenhuma Reprovação & 195 & 39.1 & 224 & 46.0 \\
1 Reprovação & 165 & 33.1 & 157 & 32.2 \\
2 Reprovações & 99 & 19.8 & 79 & 16.2 \\
3 ou mais Reprovações & 40 & 8.0 & 27 & 5.5 \\
\hline
\end{tabular}

\section{Posição na Fratria}

Do total de sujeitos que responderam a este item (972), $88.0 \%$ deles $(n=859)$ têm irmãos e $12.0 \%$ $(\mathrm{n}=117)$ são filhos únicos.

Pode-se observar uma diferença significativa $(P<0.05)$ entre os sujeitos com irmãos e os sujeitos filhos únicos, sendo que estes últimos têm melhor aproveitamento escolar (menor número de reprovações).

\section{Estatuto Profissional do Pai}

$\mathrm{Na}$ distribuição dos indivíduos pelos cinco níveis profissionais previamente por nós delimitados verifica-se que a maioria $(n=479,54.5 \%)$ dos pais dos indivíduos pertencem ao nível 4 , i.e., pais que trabalham no comércio e industria.

\section{Quadro 4 \\ Distribuição dos Sujeitos em função do Estatuto Profissional do Pai}

\begin{tabular}{|lrr|}
\hline \multicolumn{1}{|c}{ Estatuto Profissional } & $\mathrm{n}$ & \multicolumn{1}{c|}{$(\%)$} \\
\hline 1. (Alto) & 58 & 6.6 \\
2. (Médio Alto) & 153 & 17.4 \\
3. (Médio) & 151 & 17.2 \\
4. (Médio Baixo) & 479 & 54.5 \\
5. (Baixo) & 38 & 4.3 \\
\hline
\end{tabular}

Verifica-se uma associação altamente significativa $(\mathrm{P}<0.001)$ entre o insucesso escolar e o cstatuto profissional dos pais, nos escalões Baixo e
Médio Baixo ou, por outras palavras, verifica-se uma tendência para o sucesso nos filhos cujos pais se situam nos escalões Alto e Médio Alto.

\section{Estatuto Profissional da Mãe}

A distribuição das mães pelos diferentes nívcis profissionais é, tal como na dos pais, irregular e salienta-se o grande número de indivíduos cujas mães são «domésticas».

\section{Quadro 5 \\ Distribuição dos Sujeitos em função do Estatuto Profissional da Mãe}

\begin{tabular}{|lrr|}
\hline \multicolumn{1}{|c}{ Estatuto Profissional } & \multicolumn{1}{c}{$\mathrm{n}$} & $(\%)$ \\
\hline 1. (Alto) & 18 & 2.0 \\
2. (Médio Alto) & 92 & 10.0 \\
3. (Médio) & 119 & 12.9 \\
4. (Médio Baixo) & 198 & 21.5 \\
5. (Baixo) & 84 & 9.5 \\
6. (Doméstica) & 410 & 44.5 \\
\hline
\end{tabular}

A análise do Teste Qui-Quadrado indica uma relação altamente significativa $(\mathrm{P}<0.001)$ entre a variável «reprovaçōes» e a variável estatuto profissional da Mãe, mas só uma análise mais cuidada conduz à compreensão desta relação. Comparámos então o grupo de sujeitos sem nenhuma reprovação e o grupo de sujeitos que tinham tido duas ou mais reprovações e é a estes grupos que a seguir nos referimos.

A primeira questão que tentámos averiguar era se haveria diferenças de aproveitamento escolar entre os filhos cujas mães trabalham (níveis profissionais $1,2,3,4,5$ ) e os sujeitos cujas mães estão em casa, sendo domésticas. A análise revelou uma associação altamente significativa $(\mathrm{P}<0.001)$, no sentido de que os filhos das mães que trabalham têm um aproveitamento escolar inferior ao dos filhos de mães «domésticas».

Se é verdade que se verifica uma diferença altamente significativa entre os sujeitos cujas mães trabalham e os sujeitos cujas mães estão em casa sendo domésticas, a verdade é que a situação «trabalhar fora de casa» é em si mesmo complexa. Verifica-se uma difcrença igual e altamente significativa $(\mathrm{P}<0.001)$ entre os filhos das mães que 
trabalham em niveis profissionais elevados (níveis 1 e 2) e os filhos cujas mães trabalham em profissões de nível inferior (4 e 5), sendo que estes últimos têm um aproveitamento escolar inferior que se traduz por um maior número de duas ou mais reprovações e um menor número de zero reprovações.

Depois de verificada a importância de se considerarem os diferentes níveis profissionais da mãe para a compreensão do efeito desta variável no fenómeno sucesso/insucesso escolar, comparamos ainda o número de reprovaçōes dos filhos cujas mães trabalham em profissões de nível superior (1 e 2) com os filhos de mães domésticas. Podemos verificar que os primeiros (mães com profissões de altos níveis) tĉm aproveitamento escolar superior e estatisticamente altamente significativo $(\mathrm{P}<0.001)$ comparado com os sujeitos cujas mães são domésticas.

Assim, e se é verdade que os filhos de mães que trabalham têm rendimento escolar inferior ao dos sujeitos cujas mães são domésticas, quando se comparam estes últimos com os filhos das mães do nível profissional superior são os filhos destas que têm melhor aproveitamento.

\section{Grau de Instrução do Pai}

A distribuição dos pais pelos difcrentes graus de ensino é variável, salientando-se que a maioria dos pais $(n=583,62,9 \%)$ frequentou apenas o ensino primário, enquanto apenas 142 pais $(15,3 \%)$ frequentaram o ensino superior.

$\mathrm{O}$ facto de ter sofrido reprovações relaciona-se de modo estatístico e altamente significativo $(\mathrm{P}<0.001)$ com o grau de instrução do pai e no sentido esperado: os filhos dos pais de nível cultural mais elcvado são os que têm menor numero de reprovações e, portanto, melhor aprovcitamento escolar.

\section{Grau de Instrução da Mãe}

A distribuição das mães pelos diferentes nívcis de ensino é, tal como a distribuição dos pais, variável, sendo ainda mais saliente a irregularidade já que $70 \%(n=666)$ das mãcs frequentaram apenas o ensino primário, e é ainda menor o númcro das mães que atingiram o ensino superior $(n=96$, $10.1 \%)$.
A relação que o número de reprovações sofridas estabelece com o grau de instrução da mãe é estatisticamente altamente significativa, e estará muito próxima da influência que o grau de instrução do pai exerce: o sentido é sempre para o maior aproveitamento escolar (menor número de reprovações) quando se sobe no grau de instrução da mãe.

\section{ANÁliSE DA AUTO-AVALIAÇÃO DO APROVEITAMENTO ESCOLAR}

\subsection{Características do fenómeno}

$\mathrm{Na}$ análise do fenómeno de auto-avaliação do aproveitamento escolar vcrifica-se a existência de um grande número de sujeitos $(n=697,70.5 \%)$ que considera o seu aproveitamento escolar Razoável, enquanto apenas $3.9 \%(n=39)$ o classifica de Muito Bom, e $5.6 \%(n=55)$ o consideram Insuficiente e Mau. Se atendermos ao facto de serem $19.9 \%$ $(n=197)$ os que classificam de Bom, verifica-se uma tendência geral a uma auto-avaliação positiva do aproveitamento escolar, pois $24.9 \%$ dos sujeitos $(n=254)$ têm duas ou mais reprovações e apcnas $5.6 \%(\mathrm{n}=55)$ considera o seu aproveitamento cscolar Insuficiente e Mau (cf. Quadros 1 c 6)

$$
\begin{gathered}
\text { Quadro } 6 \\
\text { Distribuição dos Sujeitos em função } \\
\text { da Auto-Avaliação }
\end{gathered}
$$

\begin{tabular}{|lrr|}
\hline $\begin{array}{c}\text { Auto-Avaliação } \\
\text { Aproveitamento Escolar }\end{array}$ & $\mathrm{n}$ & $(\%)$ \\
\hline Muito Bom & 39 & 3.9 \\
Bom & 197 & 19.9 \\
Razoável & 697 & 70.5 \\
Insuficiente & 47 & 4.8 \\
Mau & 8 & 0.8 \\
\hline
\end{tabular}

Procurou-se saber se existe uma associação $\mathrm{cn}$ tre a auto-avaliação geral que 0 aluno faz do seu aproveitamento escolar e as reprovaçōes sofridas. Comparamos então o grupo de sujeitos sem nenhuma reprovação com o grupo de sujeitos com 
duas ou mais reprovações, excluindo da análise os que se auto-avaliam como tendo um aproveitamento «Razoávcl». Verificou-se que o grupo de sujeitos com reprovações tem tendência a auto-avaliar-se positivamente (Muito Bom e Bom), para uma probabilidade próxima de $\mathrm{P}<.05$, o que contraria a nossa expectativa. (Pensamos que este dado deve ser visto à luz do facto de que as reprovạções podem não ser recentes).

Quadro 7

\begin{tabular}{|l|rr|rc|}
\hline Reprovações & \multicolumn{4}{|c|}{ Auto-Avaliação } \\
& \multicolumn{3}{|c|}{ do Aproveitamento Escolar } \\
\hline & $\begin{array}{r}\text { Muito Born/Bom } \\
\text { n }\end{array}$ & \multicolumn{2}{|c|}{$\begin{array}{c}\text { Insuficiente/Mau } \\
\text { n }\end{array}$} & $(\%)$ \\
\hline Nenhuma & 122 & 71.0 & 22 & 55.0 \\
Duas ou mais & 50 & 29.0 & 18 & 45.0 \\
\hline
\end{tabular}

Na análise da distribuição percentual em função do sexo verifica-se que não existem difercnças estatisticamente significativas:

\section{Quadro 8}

Distribuição dos Sujeitos em função do Sexo e da Auto-Avaliação

\begin{tabular}{|l|rr|rr|}
\hline Auto-avaliação do & \multicolumn{2}{|c|}{ S. Masculino } & \multicolumn{2}{|c|}{ S. Feminino } \\
Aproveitamento Escolar & \multicolumn{1}{|c|}{$\mathrm{n}$} & $(\%)$ & \multicolumn{1}{c|}{ n } & $(\%)$ \\
\hline Muito Bom & & & & \\
Bom & 24 & 4.8 & 15 & 3.1 \\
Razoável & 101 & 20.2 & 96 & 19.7 \\
Insuficiente & 348 & 69.6 & 348 & 71.5 \\
Mau & 22 & 4.4 & 25 & 5.1 \\
\hline
\end{tabular}

\subsection{Contribuição das variáveis em estudo para o fenómeno}

Procurámos as associações estatisticamente significativas entre a auto-avaliação e outras características do sujeito.

A auto-avaliação do aproveitamento escolar não está associada de forma estatisticamente significativa com as seguintes variáveis: sexo; número de reprovações; posição na fratria; posição dos pais face ao trabalho; estatuto profissional dos pais; composição do anel familiar; situação conjugal dos pais; inserção familiar.

Porém, a auto-avaliação do aproveitamento escolar está associada de modo estatisticamente significativo com as variáveis: idade; estatuto profissional da mãe; grau de instrução dos pais. Os graus de significância são apresentados no Quadro 9.

\section{Idade}

Verifica-se uma diferença estatisticamente significativa $(\mathrm{P}<0.05)$ entre a avaliação que os sujeltos de 12-13 anos fazem do seu aproveitamento escolar e a que fazem os alunos de mais de 16 anos, sendo que os primeiros avaliam mais positivamente o seu aproveitamento do que os mais velhos. A análise foi feita comparando os sujeitos agrupados nas seguintes categorias de Auto-Avaliação: «Muito Bom/Bom», «Razoável» e «Insuficiente/Mau».

\section{Grau de Instruçäo Pai}

A Auto-Avaliação do Aproveitamento Escolar relaciona-se com o grau de instrução do pai de modo muito significativo $(\mathrm{P}<0.01)$ no sentido de que comparando os filhos dos pais que não sabem ler e escrever e os que têm a $4^{\text {a }}$ classe com os que

Quadro 9

Associaçâo estatisticamente significativa entre a Auto-Avaliação do Aproveitamento Escolar e Variáveis relativas ao Sujeito (Teste X2)

\begin{tabular}{|lrcr|}
\hline & X2 & G.L. & P \\
\hline Idade & 19.903 & 6 & $0.002 * *$ \\
Estatuto Profissional da Mãe & 14.082 & 6 & $0.028 *$ \\
Grau de Instrução do Paĩ & 32.449 & 12 & $0.001 * *$ \\
Grau de Instrução da Mãe & 29.977 & 12 & $0.003 * *$ \\
\hline
\end{tabular}

* $\mathrm{P}<0.05 ; * * \mathrm{P}<0.01 ; * * * \mathrm{P}<0.001$ 
frequentaram o ensino médio e superior, os primeiros auto-avaliam o seu aproveitamento escolar mais frequentemente, e de modo acima do esperado, como sendo insuficiente e mau.

\section{Grau de Instrução da Mãe}

A Auto-Avaliação do aproveitamento escolar relaciona-se de modo muito significativo $(\mathrm{P}<0.01)$ com o grau de instrução da mãe, verificando-se com mais clareza a relação nível cultural inferior/auto-avaliação negativa, salientando-se também para os sujeitos cujos pais têm frequência do ensino médio e superior uma tendência a avaliar-se mais positivamente do que o esperado.

\section{Estatuto Profissional da Mãe}

A auto-avaliação está associada estatisticamente de forma significativa $(\mathrm{P}<.05)$ com o estatuto profissional da Mãc. Verifica-se que os sujeitos que se auto-avaliam mais negativamente (Insuficiente ou Mau) são filhos de Mães Domésticas e os sujeitos que se auto-avaliam muito positivamente (Muito Bom on Bom) são filhos de mães cujo nível profissional é elevado (Alto ou Médio Alto).

\section{CONCLUSŌES E IMPLICAÇŌES PEDADÓGICAS}

Os resultados encontrados na presente investigação apoiam os resultados de outros autores atrás citados e permitem concluir o seguinte:

- Verifica-se uma maior probabilidade de ocorrência de Insucesso Escolar, medido este através do número de reprovações escolares, nos adolescentes do sexo masculino e naqueles cujas famílias têm mais do que um filho, se situam num escalão sócio-profissional mais baixo e cujos Pais têm um nível de instrução escolar inferior.

-Verifica-se uma maior probabilidade de o adolescente se auto-avaliar mais positivamente nas idades iniciais da adolescência e naqueles cujos Pais têm um nível de instrução escolar mais elevado.

- O factor sócio-cultural (profissão e nível de escolaridade) dos Pais revelou contribuir mais para o fenómeno do Insucesso Escolar e da Auto-Avaliação do que o factor ligado à composição do anel familiar (presença ou ausência dos pais no quadro familiar).

- O fenómeno da Auto-avaliação não está na dependência, em termos estatísticos, do estatuto sócio-económico, contrariamente ao que acontece com o fenómeno do Insucesso Escolar.

- A auto-avaliação não está associada, de forma estatisticamente significativa, com o número de Reprovações Escolares, não estando portanto o auto-conceilo que o adolescente faz do seu próprio aproveitamento escolar na dependência directa do número de reprovações efectivamente sofridas.

-. Os adolescentes cujas mães exercem uma profissão têm rendimento escolar inferior àqueles cujas mães são domésticas, porém quando se comparam estes últimos com os filhos de mães cuja profissão se situa num escalão sócio-profissional elevado, são os filhos destas que apresentam meIhor rendimento escolar. São também os filhos destas que se auto-avaliam mais positivamente.

- Conclui-se pelo carácter selectivo da Escola diferenciando em função do meio sócio-familiar dos estudantes. Põe-se em evidência a importância do factor «estatuto sócio-cultural elevado dos Pais» enquanto facilitador do sucesso escolar.

Os resultados empíricos encontrados apontam para uma dimensão que não pode ser excluída de qualquer abordagem teórica explicativa do fenómeno do sucesso versus insucesso escolar e, consequentemente, pensamos que também não deverá ser excluída da reflexão mais genérica sobre a Formação dos Professores e de outros técnicos ligados à problemática da Escola.

A evidência por nós demonstrada, através da pesquisa, de que aspectos culturais e sociais se associam à problemática do insucesso escolar e da auto-avaliação do aluno - não podendo estes ser explicados apenas em termos individuais (adolescentes dotados/não dotados) - aponta para a necessidade de que estes aspectos sejam integrados, enquanto áreas de reflexão, na Formação de Professores. Se não pomos em dúvida a extrema importância da dimensāo pedagógica (técnicas e tecnologicas pedagógicas, relação professor-aluno, etc.) pensamos também que a Escola, enquanto niveladora das diferenças sociais existentes e não transformadora dessas mesmas diferenças, deve ser 
repensada, ou ainda, parafraseando Bernstein (1977), «para que a cultura do mestre se torne parte integrante do mundo da criança, é necessário primeiro que a cultura da criança faça parte integrante do mundo do professor».

\section{BIBLIOGRAFIA}

Avanzini, G. (S/D) - O Insucesso escolar. Editorial Pórtico - Lisboa.

Bernstein, B. (1977) - Langage et Classes Sociales. Paris, Minuit.

Bcrzonski, M. D. (1981) - Adolescent Development. New York, MacMillan Publ.

Grácio, S.; Miranda, S. (1977) - Insucesso Escolar c Origem Social: Resultados de um Inquérito - Piloto. Análise Social nº51, II, Vol. XIII, 3², 721-727.

Leitão, L. M.; Abreu, M. V. (1985) - Insucesso Escolar: causas ou circunstâncias? Contribuição para uma análise relacional. Actas do $1^{\underline{0}}$ Encontro sobre Intervençäo Psicológica na Educação, 125-150.

Morrow, W.; Wilson, R. C. (1961) - Family Relations of Bright High Achieving and under Achieving High School Boys. Child Development, 32, 501-509.

Peixoto, L. M. (1984) - Autoestima e rendimento escolar. Trabalho Final do Curso de Peritos Orientadores, I. O. P. - Lisboa.

Pereira, F.; Martins, M. A. (1978)—O Insucesso Escolar $\mathrm{e}$ as suas explicações. Críticas e algumas teorias. Análise Psicológica, Vol. II, № 1; 33-56.

Pereira, F.; Martins, M. A. (1978) - Apresentação. Análise Psicológica. Vol. II, № 1, 5-9.

Rafolovich, N. L. (1980) - Actividade Profissional da Mãe e escolaridade das crianças. Análise Psicológica, № 2, Série I, 235-241.

Robinson, W. P. (1978) - O desinteresse escolar no ensino sccundário. Análise Psicológica, Vol. II, №1, 23-32.
Stuki, J. D. (1983) - Dynamique familiale de l'échec scolaire. Confrontations Psychiatriques, № 23, 27-57.

\section{RESUMO}

Numa amostra representativa do universo total dos estudantes frequentando os estabelecimentos oficiais do Concelho de Matosinhos, com idades compreendidas entre os 12 e os 19 anos estuda-se as características de dois fenómenos: o Insucesso Escolar, medido através do número de reprovaçōes ocorridas no conjunto da sua escolaridade e Auto-Avaliação geral que os adolescentes fazem do seu aproveitamento escolar. Procura-se encontrar a associação estatística entre estes dois fenómenos e outras características dos sujeitos, nomea damente as ligadas à composição do anel familiar, bem como ao estatuto sócio-cultural dos Pais (nivel profissional e escolar dos pais). Verificou-se que $57,5 \%$ dos adolescentes já tiveram pelo menos uma reprovaçâo na sua vida escolar, que os rapazes sofrem mais reprovações $e$ que a probabilidade de ocorrência de insucesso (reprovaçöes) sobe à medida que se desce no nivel sócio-cultural dos pais. Póe-se em evidência o papel do estatuto da mäe quer para o insucesso quer para a auto-avaliação.

Os resultados confirmam resultados encontrados por outros autores $e$ as teses a favor do carácter selectivo da Escola diferenciando em função do meio sócio-familiar.

\section{ABSTRAC'T}

The purpose of the present study is to evaluate the school achievement and the academic performance self- evaluation, as a function of demographic variables related to the adolescent families. The sample consisted of 994 adolescents with ages between 12 and 19 years and throughout all grades of Portuguese high school. The study enhances the importance of family socio-cultural status on under-achievement and academic performance self-evaluation. 